\section{Presentation of the Microscopy Image}

Robert V. Blystone, Trinity University

Microscopists have special challenges when presenting image data to audiences. Issues such as image size, resolution, and labeling are related to the format of the presented image. Contact prints, transparencies, $35 \mathrm{~mm}$ film, and projected video of digital images are some of the output options possible for microscopy presentation. This brings us to a question which Jonathan Krupp of the University of California, Santa Cruz, recently posed to the Microscopy listserver:

"In this age of digital imaging, is a film recorder still useful? The last presentation I went to was all PowerPoint 'slides', but shown directly

from a computer to a video projector, no film to be seen."

The question evokes reminiscence on my part for a moment. Older microscopists will remember the "joy" of arranging for a lantern slide projector needed to show those wonderfully sharp, large glass lantern slides. Lugging around those heavy yellow boxes of lantern slides with their silver, black, or yellow bindings was no easy trick. I still remember with rapture seeing a demonstration of making a contact print on a sheet of orthographic EM film of $35 \mathrm{~mm}$ panchromatic negatives produced from a quality, labeled photographic print. One could easily spend all day and night in the darkroom executing this four step process. But the result was with labeled, formatted, and convenient black and white presentation $35 \mathrm{~mm}$ slides.

Today, with available digital imaging processing, it is possible to go from microscope to presentation without the use of film, wet photographic chemistry, or a darkroom, and to do it in 30 minutes. All that is needed is to frame grab the image, take it to Adobe Photoshop for enhancement and labels, then organize it with a presentation manager such as Microsoft PowerPoint, and output the results on a screen with a digital video projector. In a period of thirty years we have gone from big heavy boxes of glass slides to five megabyte digital image files on a Zip disk. And in the middle of this transition is the relatively expensive film recorder.

Krupp asks a very good question. I have been on both sides of this issue of how best to prepare imagery for presentation. At the center of this question is the use of a digital presentation manager such as Microsoft PowerPoint. Once the digital "slides" have been assembled, edited, labeled, and the like, the PowerPoint file can be output to paper, transparency, film, computer screen, or video projector. A quick overview of these formats follows.

Paper:

I often output my PowerPoint slide presentations to paper as thumbnail images. I give handouts of the thumbnails to the audience to assist their note taking and for following my presentation whether it be film or digital in nature. Or I can output full images to high quality paper for poster presentation figures. Time for printing is an issue, and for quality, access to a dye sublimation printer can be a problem.

\section{Transparencies:}

Transparencies offer many advantages: transparency projectors are ubiquitous, presentation rooms do not have to be extensively darkened, the transparency can be written on, and audience is familiar with this presentation format After a talk, it is easy to share or photocopy a transparency for anyone interested. However, transparencies are bulky and can age quickly without proper care. Quality color transparencies can be as difficult as a dye sublimation print.

Film:

Presentations based on $35 \mathrm{~mm}$ slide film are more formal than transparencies. The room needs to be darkened and a $35 \mathrm{~mm}$ slide projector made available (a problem for some). This format has excellent resolution and color depth for microscope images. Slides are compact and travel well. However, a film recorder is necessary to produce quality $35 \mathrm{~mm}$ slides (please, no camera shots off the computer screen).

\title{
SAMx
}

Are you searching for an Automation system?

Would you like EDS/WDS Imaging?

Would you like to have EDS/WDS Analysis?

\section{Then we are the company you're looking for.}

We are the leading developer of EPMA/SEM automation, imaging, and combined EDS/WDS analysis under Windows95/NT. We are the pioneers in Thin Film analysis with STRATA released in 1991. We are fully Internet compatible, all software upgrades can be downloaded directly from our web site.

We listen to our customers needs and we deliver. Here are just a few:

XMAS Automation: We can upgrade your EPMA / SEM equipped with WDS.

PCIMAX with IDFIX: Get your SEM equipped with imaging and combined EDS.

TN2WIN and KV2WIN: Convert your old TRACOR/KEVEX data files to PC.

STRATAGem: Our 2nd generation of Thin Film STRATA is ready. Get your copy today.

For more detailed information on our products, we invite you to visit our web site at: www.samx.com

Please be sure to stop by our Booth \#236 at Microscopy \& Microanalysis '98 in Atlanta for your personalized demonstration. We look forward to seeing you there.

\section{SAMx Support for Applications in Microanalysis and $\mathbf{x}$-ray}

4, rue Galilée / 78280 Guyancourt - France / Tel: 011331305790 25 / Fax: 01133130489565 / email: jfthiot@samx.com Bldg. M2048, Swarr Run Road, Lancaster PA 17601 / Tel.: (717)299-0599/ Fax: (717)299-2022 / email: jbarney@samx.com 
Computer screen and video projection:

Most large computer capable television screens ( 35 inch or larger) are not commonplace and much too heavy to move. Video projectors for digital interface are quite compact and during the course of the last five years have become widespread. Some models rival overhead projectors in brightness and a few models can work at pixel sizes greater than 640 by 480 . But even the best projectors working at 1000 line (pixel) resolution fall far short of slide film resolution (about 3000 lines). The video projectors are still problematic in terms of set-up when compared to overhead or slide projectors.

Addressing Krupp's question directly as to the utility of a film recorder boils down to whether the output should be plastic or bytes. Below are deciding factors in terms of which format I use:

1) How solid is the technology at the point where the lecture is to be given? The concerns here include the following. I have a Macintosh computer. They always use $\mathrm{PC}^{\prime} \mathrm{s}$, and the right cable is not there. I made my presentation on Office 98 under Mac OS 8.1 and they have System 7.1 loaded with PowerPoint 3. The mismatches can be endless and much harder to resolve when compared to changing a bulb in a slide projector.

2) Is the Powerpoint presentation better than using the slides? Is animation a key feature of the presentation? Or sound? Are the flying bullets more important than the sharpness of the slide? How important are screen lumens? Bright slides work better than dim video. It is hard to beat 3000 plus lines of slide resolution when compared to 640 by 480 pixels. They may have a video projector with a bulb 500 hours on the other side of dead.

3) How important is it to fix the presentation on the fly? You sized your slides to work in a 30 foot long room and you find yourself in a 100 foot hall. You cannot resize $35 \mathrm{~mm}$ slides two hours before the lecture. You can extensively rearrange and even (re)edit a digitally presented lecture in an airplane seat, but you sure can't do that with $35 \mathrm{~mm}$ slides.

4) Can your presentation work best with twin screens: two images at a time?
This is usually a snap with $35 \mathrm{~mm}$ slides, but it is still pretty difficult with video projection.

5) The audience must always be kept in mind. Recently I saw a really "slick" computer controlled presentation. Some in the audience were put off by the excellent presentation because it was too slick. An analysis might help here: it was a research lecture being used to demonstrate an applicant's wares for a tenure-track teaching position. The students in the audience thought it was great. Older faculty who did not use computer media thought it was needlessly glitzy. Media proficient faculty were more focused on how the presentation was assembled rather than the message. Predictable, but it still caught me of guard.

Back to the question: should you spend $\$ 10,000$ or so to have a film recorder? The given is that the presentation will be digitally assembled. Far less can go wrong with a slide presentation. You can focus on the images displayed on the screen and weave the story. Organizing a talk from many $35 \mathrm{~mm}$ slides on a light box is still easier that coaxing the computer to yield its multiple images. With the digital output, you are bound by the technology as a prop. Props complicate the delivery.

The face of microscopy is changing. We can watch calcium flow through cells with confocal microscopy. We can three dimensionally reconstruct serial sections through time. Static $35 \mathrm{~mm}$ slides cannot do this kind of imagery justice. On the other hand, pinpoint sharp autoradiographs are far better on film.

I use both presentation formats and will continue to do so for the next several years. For really important lectures on the road, I have $35 \mathrm{~mm}$ slides for backup, and I take the digital presentation in both Mac and PC outputs. I still own a lantern slide projector with three different focal length lenses. Perhaps in five or more years I may put my digital film recorder next to my lantern projector in the back of the storeroom. Given the speed of technology, I might even have my video projector on the dusty shelf as we argue about which holographic projector is best for microscope image output.

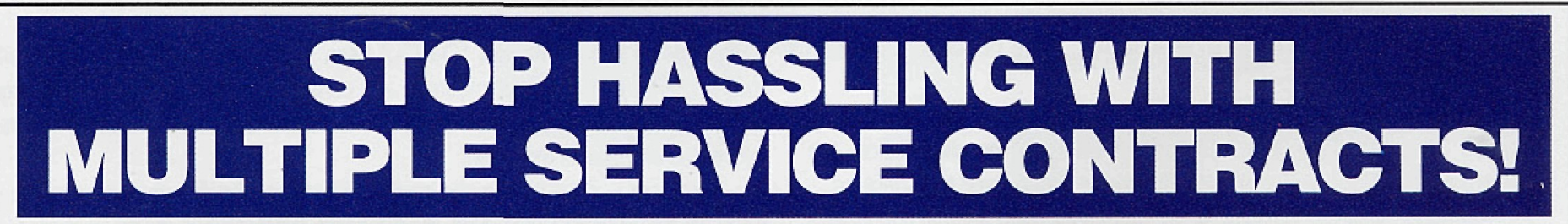

START by putting all of your instruments under one contract with MAS (regardless of make or model). Our expert EM SERVICE GROUP has the knowledge and skill to keep your instrumentation working at its best.

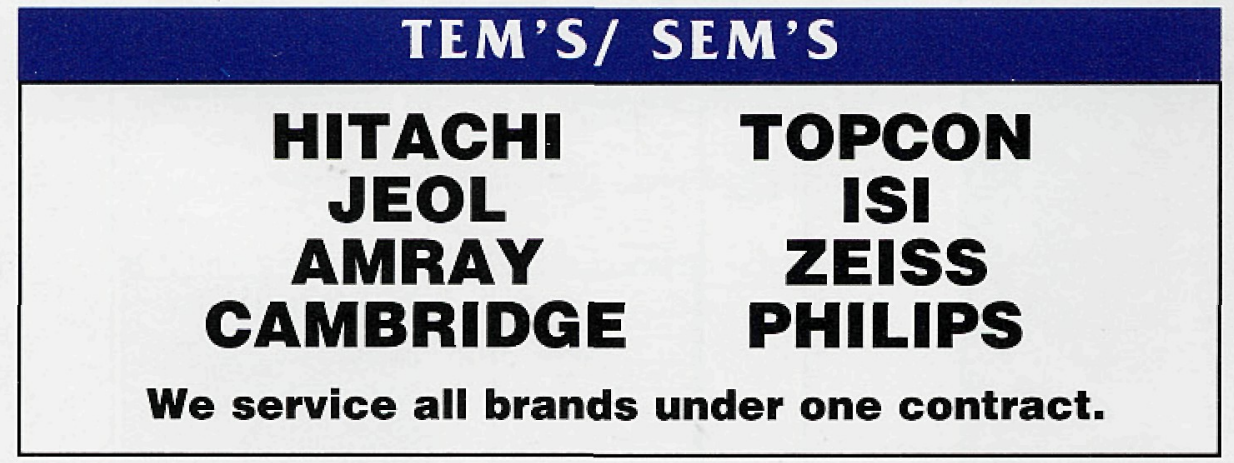

PREP EQUIPMENT

ULTRAMICROTOMES DUPONT \& RMC VACUUM COATERS SPUTTER COATERS MECHANICAL PUMPS TURBO PUMPS PLASMA ASHERS

\section{WE SERVICE COMPUTER CONTROLLERS} BEAM BLANKERS WATER CHILLERS
Contracts and On-Demand

Emergency Service at

Reasonable Rates from

Factory Trained Specialists.

\section{1-800-421-8451}

3597 Parkway Lane • Suite 250 • Norcross, Georgia 30092 • 770-448-3200 • FAX 770-368-8256 or 616 Hutton Street • Suite 101 • Raleigh, North Carolina 27606 • 919-829-7041 • FAX 919-829-5518 ADVANCED ANALYTICAL PRODUCTS AND SERVICES 